\title{
Management of indicators of loss and dilution in a mining activity
}

\author{
Skënder Lipo" ${ }^{1}$, Nevina Polo ${ }^{2}$ \\ ${ }^{1}$ Faculty of Geology and Mining, Department of Mineral Resources Engineering, \\ Tirana, Albania \\ ${ }^{2}$ Faculty of Geology and Mining, Department of Energy Resources, \\ Tirana, Albania
}

\begin{abstract}
Mining assets are unrepeatable and an important source for the development of a country. Their industrial exploitation is based on mining, metallurgical, economic, environmental, and state social factors. Mining factors such as production capacities, mining costs and the realization of indicators of loss and dilution are the determinants of the success of a mining activity. The value of a mining project, which is based on limited reserves, is very sensitive to loss indicators and dilution, as each lost tonnage of minerals affects the value of the resources. In this article, we will discuss the degree of impact of the above factors, while paying attention to achieving the most optimal indicators of loss and dilution. In mining activities with limited reserves and where the value of a mineral tone extracted from the ground is high, is required to increase the extract / loss ratio and maintaining a fair ratio between the indicators of loss and dilution
\end{abstract}

Keywords: mineral losses, dilution, cutoff grade

\section{Introduction}

The earth's rock material, where a mineral is found, form mineral deposits, the object of the mining and mineral processing industry. The distribution of mineralization within a mining deposit is very heterogeneous and creates different concentrations of mineralization. The concentration rate is the grade of the metal content. When the mineralized material has such a grade of metal (cut - off grade) that can be used to utilize an economic gain, this part of the deposit is called a mineral resource and the mineralized material is called ore. The rest of the deposit, with lower content of metal grade, is considered noneconomic and in mining terminology is called waste. The cut-off grade term is used in the mineral extracting industry to distinguish the mineralized material (ore) that can be used profitably from the rest (waste) that does not represent an economic interest when the mining deposit is estimated. When talking about exploitation of mineral resources, different concepts are encountered between the wealthy landowner (the state) and the private companies working on their extraction. Mining companies orient the works to maximize profitability under mining activity. Assessing the mining costs and price of metals, the underground mining operations of high grade metal bodies (A. Khodayari, A. Jafarnejad, 2012) are oriented. This action leaves in the underground, parts of the mineralized material that has metal content smaller than the selected cut of grade. On the other hand, the state is interested in increasing the value of the mineral resource and through its organisms, exercising control and requires the extraction from the underground to the low grade ore reserves.

From the point of view of the public interest, dominates the opinion that the extraction and acquisition of mining assets, as a national nonrecurring wealth, must be rationally realized. Even the mining from the underground to the poor onesource reserves starts with the conclusion of the contracts in determining the boundaries of the mine and lower taxes. Only like this the mining enterprises will be interested in extracting from the underground even the poor ores, while the state has realized the ultimate goal, rational acquisition of mining assets. 
Mining activity studies set the value of a resource by the profit obtained in a mining activity. Mining companies can increase profits by utilizing mineral reserves of high content, which reduces costs in producing a tone of concentrate and shortens the life of the mine. Such action reduces the reserves of a mining source, thus decreasing its value (S. Lipo, N. Polo, 2018). When talking

\section{Briefly about break even cutoff grade}

The most important moment during the design of a mining activity is to define the boundary of the commercial component content, which separates mineralized material in ore and waste. So the key variable is the concentration, the minimal industrial grade of the metal in the mineralized material. Costs for extraction and processing of this material (ore) are recovered from the value that will be obtained from the sale of the produced product. In a broader definition, cut-off grade (Taylor, H.K. 1972), is any grade that is used to separate two courses of action, that is, to use or not extract from the underground, enriching it, or sending it to the dump of waste.

In the finished works in this field, the cut-off grade parameter dependsby the value of melted ore (metal) and the costs for the production of this final product. To better understand the cut-off grade theory of concrete resource, we are giving in asimplified form, formulas for calculating the value of the ore and the cost for the production of the final product, so:

$$
\begin{aligned}
& V=\bar{g} \cdot y \cdot P_{m} \\
& C_{T}=C_{M}+C_{P}+C_{S h}
\end{aligned}
$$

\section{Where}

$V$ - Ore's value; $\bar{g}$ - the content of the metal in the ore; $y$ - the recovery indicator in metallurgy; $P_{m}$ - Price per a tone melted ore (metal); $C_{T}$ The total cost of producing the final product $C_{M} ; C_{C} ; C_{S h}{ }^{-}$respectively the costs for the extraction, enrichment and melting of ore.

Depending on the formulas above, is calculated the minimum industrial content of the metal in the ore (break even cutoff grade) with the equation:

$\bar{g} \cdot y \cdot P_{m}=C_{M}+C_{P}+C_{S h}$, and we have

$g=\frac{C_{M}+C_{C}+C_{S h}}{y \cdot P_{m}}$ about increasing the performance in mining processes, it should not be enough just to control spending and improve the cost of preparatory mining works, drilling operations and mineral enrichment costs. Particular care must be taken in the realization of mineral extraction indicators and indicators of loss and dilution in the mineral extraction and enrichment process.

The minimum industrial content $(\mathrm{g})$ indicates the minimum level of metal content in the mineralized material, which causes the material to be considered as ore and can be utilized. But a mining activity works to secure a planned profit, depending on the level of investment and the risk of returning this investment. If we accept the planned profit rate (f), we can calculate the cut-off grade that will provide us with this profit, therefore:

$$
g_{f}=f \cdot \frac{C_{M}+C_{C}+C_{S h}}{y \cdot P_{m}}
$$

In the equation (4) only the price perone tone of molten ore does not depend on the technologies selected for extraction, enrichment and melting of the ore. The fluctuations of this parameter depend on the demand and supply for a given mineral. The impact of this parameter on the calculation of the average metal content in ore is important, therefore mining companies show caution in determining the expected price volatility of the final product sales price.

The other parameters relate to the technology selected in extraction, enrichment and melting of minerals and are determinants of the success of a mining activity. In this set of parameters, mining indicators are more difficult to achieve, while metal enrichment and melting parameters are more stable.

\section{Cut - off grade and the value of a mining resource}

A mining activity consists of three distinct stages from each other and specifically from ore extraction (mining project), mineral enrichment activity, and melting activity and preparation of the final product (metal). Thus, a mining activity can be organized in three forms:

1-Mining with final product, mineral,

2-Mining + enrichment factory with final product, concentration, and

3-Mining + enrichment factory + metallurgy with final product, metal. 
Most often in the mining practice we find the variant (2). In a few cases, a mining activity can only consist of mines, with the final extracted mineral product, as this form of work provides a small profit, compared to the calculated value per single source. The third variant would be the best variant and commonly applied, when powerful investors have a mining activity supported in ore deposits with considerable reserves.

The three stages of mining activity (mining, enrichment and smelting) are subject to production constraints and in all three stages, in order to maximize the profit that can be obtained from a ton of ore. If mining activity works under Scheme (2), the most usable scheme today in our mines, then the final product would be the concentrate produced after ore enrichment. In this case, the break even cutoff grade and cut - off grade would be calculated with the equations:

$$
\begin{aligned}
& g^{c}=\frac{C_{M}+C_{C}}{y^{\prime} \cdot P_{c}} \\
& g_{f}^{c}=f^{\prime} \cdot \frac{C_{M}+C_{C}}{y^{\prime} \cdot P_{c}}
\end{aligned}
$$

Where $\quad y^{\prime}$ - recovery index in enrichment (\%); $P_{C}$ - the selling price of the concentrate, $\$ /$ ton.

Equation (5) indicates that the minimum industrial content of the commercial component (metal) is the content in which the gross value of the ore extracted from mines and enriched is equal to the cost of mining and enrichment. This content is the limit of the metal degree below which the mineral reserves would not be utilized profitably. Equation (6) indicates that the content of the commercial component (metal) is the content that will be worked, with apre-assessed profit (f ').

If we accept approximate values (each mining activity has its own specifics) of mining cost in underground mines ( $=\$ 20 /$ ton), enrichment cost $(=\$ 15 /$ ton $)$, recovery indicator $(=0.8 \%)$, the selling price of copper concentrate with an average content of $20 \% \mathrm{Cu}$. (= $1000 \$ /$ ton) and the planned profit ( $f=1.20$ ), would have the following results:

$$
g^{c}=\frac{25+15}{0.8 \cdot 1000} \approx 0.875 \% \mathrm{Cu}
$$

$$
g_{f}^{c}=f \cdot g^{c} \approx 1.05 \% \mathrm{Cu}
$$

The estimated value of the calculated minimum industrial content $\left(g^{c} \approx 0.875 \% \mathrm{Cu}\right)$ indicates that in a given copper resource must be extracted from the underground and enriched, only those parts of mineralized material having a copper content of not less than $0.875 \% \mathrm{Cu}$. The other parts of the mineralized material reserves should be left in the underground, or extracted and stored in the waste dumbs. To get the planned profit of this mining activity, the mineral that goes in the process of enrichment must have a content not less than $1.05 \% \mathrm{Cu}$.

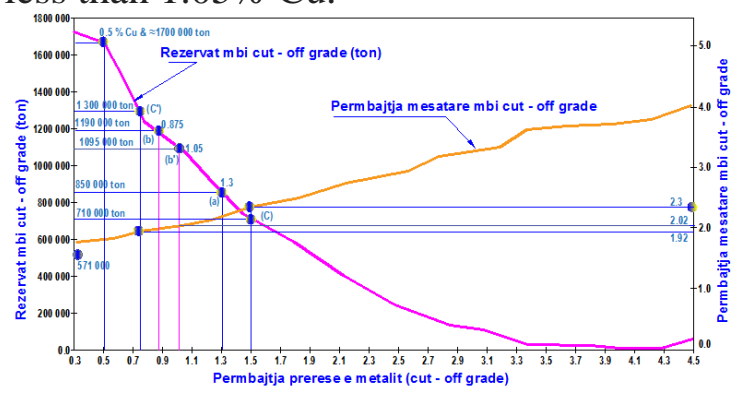

Fig. 1 Dependence of ore reserves and average metal content from cut - off grade

The two indicators estimated above are very high for their use in our copper mines. If we refer to the dependence reserve curves and the average content of metal in this ore, (see Figure 1), build for a ore copper deposit in our country, we notice that the reserves curve on the cut - off grade falls rapidly with the increase in the cut - off grade value. By selecting the content of about $1.3 \% \mathrm{Cu}$ (point "a" in the curve), the reserves of this resource will be halved and as a result, the value of this ore deposit will decrease significantly.

Selecting a small content as possible $(0.5 \% \mathrm{Cu})$ would increase resource reserves $(\approx 1,700,000$ tons), and increase the value of the ore deposit. Working with such metal content in the ore should provide extra productive cost of a ton of concentrate and a high price of metal sales.

The selling price of the product depends on the market demand and supply of a certain mineral. Although the trend of metal price fluctuations in the last 40 years has a steady growth trend, there is often a significant decline in the prices faced by difficulties in mining activities. As a result of metal price decreases in recent years, we have also closed some mines in our country.

The copper concentrate selling price, with average copper content $(20 \% \mathrm{Cu})$, is characterized by large fluctuations. This price in the last 10 years has captured values from 700 to 1400 dollars per ton. If we were to put these values in the drawings (5 and 6), keeping the other variables unchanged, we would obtain the values of minimum of gradeand cut-off grade of the metal in the ore: 
For $P_{C}=700 \$ /$ ton we will have $g^{c} \approx 1.25 \% \mathrm{Cu}$

$$
\text { and } g_{f}^{c} \approx 1.5 \% \mathrm{Cu}
$$

For $P_{C}=1400 \$ /$ ton we will have $g^{c} \approx 0.625 \%$

$\mathrm{Cu}$ and $g_{f}^{c} \approx 0.75 \% \mathrm{Cu}$

For a high price of concentrate, we have a relatively small value of the metal content in the ore, so there is an increase in mineral resource reserves. The opposite happens when the selling price of the concentrate is low. In this case from the mineralized reserves of material will only be treated as ores the ones that have higher content than $1.25 \% \mathrm{Cu}$, thus reducing the value of a mineral resource.

If the abovementioned sizes are reflected in the curvesshown in Figure 1, we note that the drop in the selling price of the concentrate at the level of $\$$ $700 /$ ton would increase the cut-off grades to $1.5 \% \mathrm{Cu}$. This increase in grade will reduce the reserves of the ore (point c) and from the source would be utilized about 710000 tons of ore with $\bar{g} \approx 2.3 \% \mathrm{Cu}$. And for a high price of the final product (in this case $P_{C}=1400 \$ /$ ton), thus for a ( $g_{f}^{c} \approx 0.75 \mathrm{Cu}$ ) cut-off grade, from the source would be utilized 1575000 tons of reserves (pointc') with an average content of $\bar{g}=1.86$ $\% \mathrm{Cu}$. We accept unchanged metal mining and enrichment indicators, and we appreciate that in the first case, the amount of metal to be sold will be 1633000 tons, while in the second case 2496 000 tons.

By comparing the amount of metal to be provided for, the difference of 863,000 tons of metal is definitive and we it not be neglected in the case of our copper mines, where the average amount of ore reserves fluctuates around one million tones. Note that even under the conditions of mining activities, working on deposits with considerable reserves, would not be acceptable to assessment as "waste" mineralized material with a grade metal $1.25 \% \mathrm{Cu}$.

\section{Management of mining processes, the basis of the success of a mining activity}

When talking about the main factors determining whether anore deposit will be used for exploitation, first the reserves of ore and the grade of metal in these reserves are estimated, thus the amount of metal in the given source. These indicators are the only asset of anore deposit.
When mineralized material in a source has high metal content, mining activity is generally profitable. The costs for extracting, enriching and smelting of mineral tones are decrease moderately, and the amount of final product (metal) obtained from the processing of each ton mineral increase.

Even the dimensions of mining deposit are very important. Undertaking a mining activity requires large spending and a long time to recover the expenses incurred. Not too small parts of the ore extract reserves, goes to cover these expenses. When the mining activity is supported in considerable reserves, the impact of capital spending on the success of a mining activity is significantly reduced and work is organized to increase the present value through improved operating costs, cut-off grade growth, by extracting high content minerals, depending on metal price fluctuations.

When the ore reserves are limited the main requirement that comes to a mining activity is to extract ore reserves with as little quantitative loss as possible but also to control the quality losses (dilution of extracted mineral).

Quantitative and qualitative losses in the mineral mining process, with underground mining works, are inevitable (S. Lipo;Kubaturat dhe rezervat, 2007). Their magnitude depends mainly on the utilization system used, the geology of the ore bodies, and size of the production units and their position in relation to the forms and dimensions of the ore bodies. Quantitative and qualitative losses are present in every production unit of mineral extraction, but appear larger in the production units located near the ore contours (Mechikov O.S. 2007).

The high quantitative losses in the underground mining process directly affect the reduction of extraction reserves of production and require the compensation of the missing production from other production units. Under the conditions where oredeposit reserves are limited, any lost tons of ore reserves will affect the economic balance of the mining activity. Even the quality loss control (dilution) is of particular concern. Dilution of mineral in the production process is associated with increased rock waste in extracted minerals. This brings negative impacts on the production of a ton of concentrate, the degradation of performance in the enrichment process, the growth of mining waste in the dumpsof enrichment factories and the increase of negative impacts on the environment. 


\subsection{Interaction between indicators of mineral losses and dilution.}

Losses and the dilution of minerals in the process of miningcannot be avoided. Their size and the ratio between the loss and dilution cannot be solved a priori. They are a function of the geological medium, the mining system, mining processes and the value of an extracted ore. In mining processes for extracting the ore, a combination of the above factors is achieved to provide low loss indicators and an optimal ratio between quantitative loss of the ore and dilution. Generally, these indicators, especially in the systems of exploitation with block or sublevel caving, clearly affect one another, where the growth of the one indicator is accompanied by the decrease of the other indicator. The reducing ofloss indicator, as the most significant indicator for the value of a manufacturing unit, in these mining systems, is mainly achieved by increasing the indicator of dilution. But even the dilution indicator cannot grow limitless, because not every increase in the dilution indicator will be accompanied by a decrease in the loss indicator.

If we refer to the dependence between the indicators of losses, dilution and the extracting ore indicator, built during the exploitation of a block with a block caving system and extracted the broken ore using the funnels,(S. Lipo,1990), we would draw these conclusions ( see figure 2):

In the process of collecting the broken ore,we distinguish two stages of extracting the ore.

The first phase consists, in the extraction of pure ore, startingthecollection of the broken ore, until the moment of occurrence in the outlet of the dilution mass. During this phase, about 53\% of the bloc reserves (point a) have been extracted for the block. Until now, the dilution mass has not reached the extraction outlet, while the loss rate is rapidly reduced to $47 \%$.

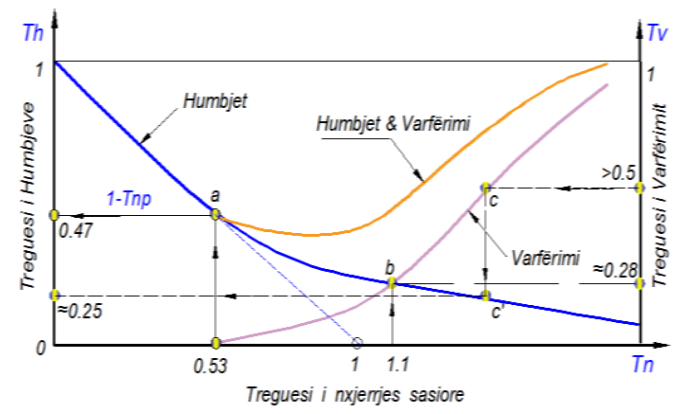

Fig. 2 Relations between mineral extraction indicators and losses and dilution during mining with block caving methods.
The second phase begins with the manifestation of dilution mass in the extraction outlet. The dilution curve begins to grow slowly. With the continuation of the extraction of the ore together with the dilution mass, there is a rapid growth of the dilution curve, while the decrease of losses begins to slow down (point $b$ ). With the increase in the dilution indicator, there is a drop in metal grades in mineral doses and dilution in dose increases a lot. The interruption of the extraction at the Prrenjas mine occurred when the dilution in dose amounted to about 50\%. After this point (point c), while dilution grew, the losses diminished very slowly. About $6 \%$ of the mineral remained as losses in every couple of funnels.

Although the magnitude of the indicators of mineral losses and dilution is determined by the mining and enrichment processes, the moment of break of the mineral extraction, thus the limitation of the dilution indicator, is related to economic indicators, and concretely the value of a ton of mineral and the cost of extracting and processing it. We note that the ratio between the loss indicator and the dilution indicator, especially for high value minerals, and mining activities that are supported in limited reserves should be as small as possible (Lipo S. Polo N. 2018).

\section{Conclusions:}

The tendency of mining companies to work with a high value cut-off grade increases the profitability of a mining activity, but not the value of a resource. The public interest requires the increase of the value of the ore, thus the increase of the quantity of ore reserves to be allocated for acquisition.

The improvement of economic indicators in a mining activity relying on ore deposits with limited reserves should be sought and realized mainly in improving the indicators of loss and impoverishment, mineral extraction and enrichment processes. Through the careful management of the mining and enrichment, depending on the choice of ore of the selected exploitation system, should be worked with high indicators of extracting and the ratio between the indicators of loss and dilution must be as small as possible. Thus, will be extracted even the reserves of the ore with metal grades at the minimum industrial grade limits, so the value of the source will increase.

In block and sublevels mining methods, loss and dilution indicators have a functional relation, 
which cannot be avoided. In ore deposits with limited reserves, the target is to minimize the loss indicator even by increasing the dilution indicator. But the size of dilution indicator cannot increase much because it is limited by the value of a ton mineral, the cost of extracting it, the average metal content in the production unit reserves, and the cut-off grade size.

\section{References}

[1] Taylor, H.K. 1972. General background theory of cut-off grades, Institution of Mining and Metallurgy Transactions, $\mathrm{p}$ 160-179

[2] A. Khodayari, A. Jafarnejad 2012. Cut-off grade optimization for maximizing the output rate. Int. J. Min. \& Geo-Eng, V. 46, No. 2, p 157-162

[3] Lipo. S. 1990. Analiza e humbjeve te xeherorit gjate shfrytëzimit te vendburimit te $\mathrm{Fe}$ - Ni Prrenjas, rrugët për zvogëlimin e tyre. Punim Disertacioni.Biblioteka e UP Tirane. Analysis of the loss of ore during

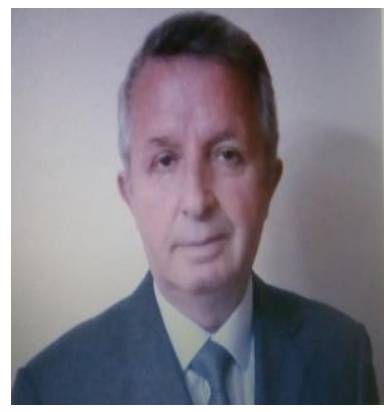

\section{Author Profile}

Prof. as. Dr. Skënder LIPO is a lecture in the Department of Mining Resources Engineering. Nowadays Prof. Lipo is chief of Department. With more than 35 year experience, Professor Lipo gives lecture in Master Diploma and School of Doctorates. He possesses good knowledge in 'Mining Measurement" and" Mining Subsidence Engineering" subjects. Professor Lipo has led 5 $\mathrm{PhD}$ students and many projects in the area of mining surveying, mining modelling and environmental protection. the exploitation of the Fe - Ni Prrenjas deposit, ways to reduce them. Works for dissertation. Biblioteka UP Tirana.

[4] Mechikov O.S. 2007. Metod upravleniya poteryami i razubozhivaniem rud pri otrabotke slozhnostrukturnykh prikontaktnykh zon. Gornyi informatsionno-analiticheskii byulleten. 4, p. 229-233.

[5] Lipo S. 2007 Kubaturat rezervat dhe humbjet e xeherorit. Tekst mesimor, Tirane. Cubatures, reserves and mineral losses. Teaching Text. Tirane

[6] Lipo S. Polo N. 2018 Assessment of underground copper deposit "Bregu i Geshtenjes". International Scientific Journal. Micro Macro \$ Mezzo Geo Information, p $89-100$.
European Economic Studies, a master Diploma at the Faculty of Economics, Tirana in cooperation with University of Bamberg, Germany She has a 16 year experience as a lecturer in the following topics: Economics and Business Administration, Economics and Natural Resources Management, and Environmental Economics
M.Sc. Nevina Polo is lecturer at the Energy Resources Department, Faculty of Geology and Mining, Tirana. She graduated as General Economist, from the Faculty of Economics, Tirana. In 2005, gained the Master of Science degree, in

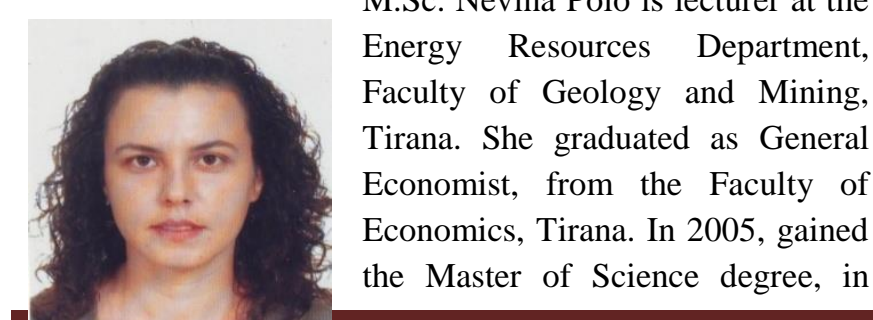

